\title{
Review Bench-to-bedside review: Oxygen as a drug
} Haim Bitterman

Department of Internal Medicine, Carmel Medical Center, The Ruth and Bruce Rappaport Faculty of Medicine, Technion - Israel Institute of Technology, 7 Michal Street, Haifa 34362, Israel

Corresponding author: Haim Bitterman, haimb@tx.technion.ac.il

Published: 24 February 2009

This article is online at http://ccforum.com/content/13/1/205

Critical Care 2009, 13:205 (doi:10.1186/cc7151)

(c) 2009 BioMed Central Ltd

\begin{abstract}
Oxygen is one of the most commonly used therapeutic agents. Injudicious use of oxygen at high partial pressures (hyperoxia) for unproven indications, its known toxic potential, and the acknowledged roles of reactive oxygen species in tissue injury led to skepticism regarding its use. A large body of data indicates that hyperoxia exerts an extensive profile of physiologic and pharmacologic effects that improve tissue oxygenation, exert anti-inflammatory and antibacterial effects, and augment tissue repair mechanisms. These data set the rationale for the use of hyperoxia in a list of clinical conditions characterized by tissue hypoxia, infection, and consequential impaired tissue repair. Data on regional hemodynamic effects of hyperoxia and recent compelling evidence on its anti-inflammatory actions incited a surge of interest in the potential therapeutic effects of hyperoxia in myocardial revascularization and protection, in traumatic and nontraumatic ischemic-anoxic brain insults, and in prevention of surgical site infections and in alleviation of septic and nonseptic local and systemic inflammatory responses. Although the margin of safety between effective and potentially toxic doses of oxygen is relatively narrow, the ability to carefully control its dose, meticulous adherence to currently accepted therapeutic protocols, and individually tailored treatment regimens make it a cost-effective safe drug.
\end{abstract}

Oxygen is one of the most widely used therapeutic agents. It is a drug in the true sense of the word, with specific biochemical and physiologic actions, a distinct range of effective doses, and well-defined adverse effects at high doses. Oxygen is widely available and commonly prescribed by medical staff in a broad range of conditions to relieve or prevent tissue hypoxia. Although oxygen therapy remains a cornerstone of modern medical practice and although many aspects of its physiologic actions have already been elucidated, evidence-based data on its effects in many potentially relevant clinical conditions are lagging behind.
The cost of a single use of oxygen is low. Yet in many hospitals, the annual expenditure on oxygen therapy exceeds those of most other high-profile therapeutic agents. The easy availability of oxygen lies beneath a lack of commercial interest in it and the paucity of funding of large-scale clinical studies on oxygen as a drug. Furthermore, the commonly accepted paradigm that links hyperoxia to enhanced oxidative stress and the relatively narrow margin of safety between its effective and toxic doses are additional barriers accounting for the disproportionately small number of high-quality studies on the clinical use of oxygen at higher-than-normal partial pressures (hyperoxia). Yet it is easy to meticulously control the dose of oxygen (the combination of its partial pressure and duration of exposure), in contrast to many other drugs, and therefore clinically significant manifestations of oxygen toxicity are uncommon. The present review summarizes physiologic and pathophysiologic principles on which oxygen therapy is based in clinical conditions characterized by impaired tissue oxygenation without arterial hypoxemia.

\section{Application}

Normobaric hyperoxia (normobaric oxygen, NBO) is applied via a wide variety of masks that allow delivery of inspired oxygen of $24 \%$ to $90 \%$. Higher concentrations can be delivered via masks with reservoirs, tightly fitting continuous positive airway pressure-type masks, or during mechanical ventilation. There are two methods of administering oxygen at pressures higher than $0.1 \mathrm{MPa}$ (1 atmosphere absolute, 1 ATA) (hyperbaric oxygen, HBO). In the first, a small hyperbaric chamber, usually designed for a single occupant, is used. The chamber is filled with $100 \%$ oxygen, which is compressed to the pressure required for treatment. With the second method, the treatment is given in a large multiplace hyperbaric chamber. The chamber is filled with compressed air while the patients

ARDS $=$ acute respiratory distress syndrome; ATA $=$ atmosphere absolute; CLP $=$ cecal ligation and puncture; CNS $=$ central nervous system; $\mathrm{DAD}=$ diffuse alveolar damage; $\mathrm{EEG}=$ electroencephalogram; $\mathrm{HBO}=$ hyperbaric oxygen; IR = ischemia and reperfusion; MOF = multiple organ failure; $\mathrm{NBO}=$ normobaric oxygen; $\mathrm{NO}=$ nitric oxide; $\mathrm{PMNL}=$ polymorphonuclear leukocyte; $\mathrm{ROS}=$ reactive oxygen species; SIR $=$ systemic inflammatory response; $\mathrm{SSI}=$ surgical site infection. 
Figure 1

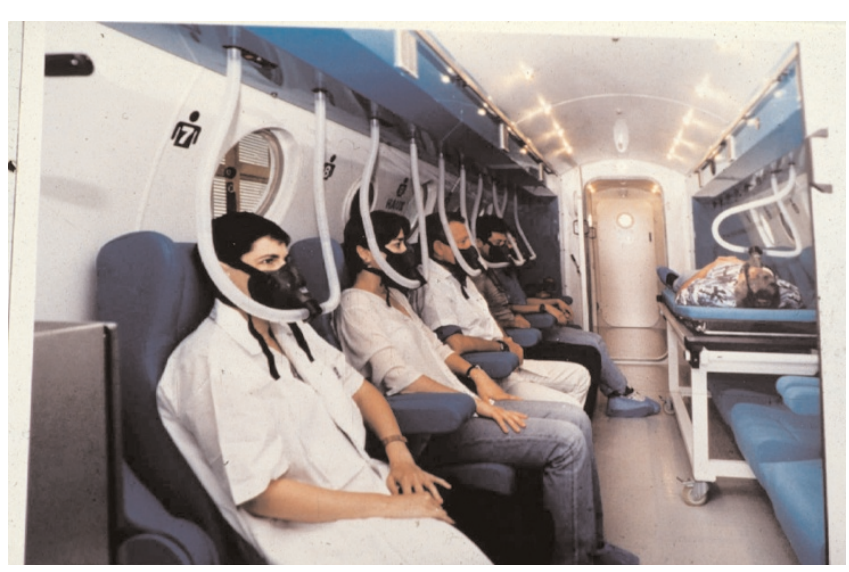

A multiplace walk-in hyperbaric chamber. The treatment pressure is attained by compressing the ambient air in the chamber. Patients are exposed to oxygen or other gas mixtures at the same pressure via masks or hoods. Many hyperbaric facilities are equipped for providing a full-scale critical care environment, including mechanical ventilation and state-of-the-art monitoring.

breathe $100 \%$ oxygen at the same ambient pressure via a mask or hood (Figure 1) [1].

\section{Tissue oxygenation}

Delivery of oxygen to tissues depends on adequate ventilation, gas exchange, and circulatory distribution. When air is breathed at normal atmospheric pressure, most of the oxygen is bound to hemoglobin while only very little is transported dissolved in the plasma. On exposure to hyperoxia, hemoglobin is completely saturated with oxygen. This accounts for only a small increase in arterial blood oxygen content. In addition, the amount of physically dissolved oxygen in the blood also increases in direct proportion to the ambient oxygen partial pressure. Due to the low solubility of oxygen in blood, the amount of dissolved oxygen in arterial blood attainable during normobaric exposures to $100 \%$ oxygen (about 2 vol\%) can provide only one third of resting tissue oxygen requirements. However, on exposure to oxygen at a pressure of three atmospheres (in a hyperbaric chamber), there is sufficient oxygen dissolved in the plasma (about 6 vol\%) to meet the average requirements of resting tissues by means of dissolved oxygen alone without contribution from oxygen bound to hemoglobin [1,2]. This is part of the rationale behind the use of hyperoxia in situations in which the hemoglobin's oxygen-carrying capacity has been impaired (for example, in carbon monoxide poisoning [3] and in severe anemia when transfusion of blood is not possible [1]).

Deliberations on the effect of hyperoxia on the availability of molecular oxygen to tissues which are based on changes in arterial blood oxygen content undervalue the main effect of hyperoxia that is related to changes in its partial pressure in the blood (Table 1). The flow of oxygen into tissues occurs by
Table 1

Alveolar oxygen partial pressure while breathing air or $100 \%$ oxygen at different ambient pressures from 1 to 3 ATA

\begin{tabular}{|c|c|c|c|}
\hline \multicolumn{2}{|c|}{ Total pressure } & \multirow{2}{*}{$\begin{array}{l}\mathrm{P}_{\mathrm{A}} \mathrm{O}_{2} \\
\text { on air }\end{array}$} & \multirow{2}{*}{$\begin{array}{l}\mathrm{P}_{\mathrm{A}} \mathrm{O}_{2} \text { on } \\
100 \% \mathrm{O}_{2}\end{array}$} \\
\hline ATA & $\mathrm{mm} \mathrm{Hg}$ & & \\
\hline 1 & 760 & 102 & 673 \\
\hline 2.5 & 1,900 & 342 & 1,813 \\
\hline 3 & 2,280 & 422 & 2,193 \\
\hline
\end{tabular}

ATA, atmosphere absolute; $\mathrm{P}_{\mathrm{A}} \mathrm{O}_{2}$, alveolar oxygen partial pressure.

diffusion. The driving force for diffusion of oxygen is determined by its partial pressure gradient between capillary blood and tissue cells and much less so by increased oxygen content [4]. Inhalation of $100 \%$ oxygen yields a 5- to 7 -fold increase in arterial blood oxygen tension at normal atmospheric pressure and may reach values close to $2,000 \mathrm{~mm} \mathrm{Hg}$ during hyperbaric exposure to oxygen at $0.3 \mathrm{MPa}$ (3 ATA). The marked increase in oxygen tension gradient from the blood to metabolizing cells is a key mechanism by which hyperoxygenation of arterial blood can improve effective cellular oxygenation even at low rates of tissue blood flow.

A recent surge of interest in the value of increasing the availability of oxygen to tissues in critical conditions yielded important studies like the one on early goal-directed therapy in sepsis [5] that assessed a resuscitation protocol aimed at increasing tissue oxygenation. Regrettably, the specific value of oxygen therapy was not assessed in this study. Yet a recent study that compared the influence of allogeneic red blood cell transfusion with 100\% oxygen ventilation in volume-resuscitated anemic patients after cardiac surgery demonstrated a superior effect of normobaric hyperoxia (NBO) on tissue (skeletal muscle) oxygen tension [6].

\section{Hemodynamic effects}

The availability of oxygen to tissues is also determined by its effects on hemodynamic variables. In healthy animals and humans, oxygen causes a temporary increase in blood pressure by increasing total peripheral vascular resistance secondary to systemic peripheral vasoconstriction [7]. This transient change is rapidly counterbalanced by a decrease in heart rate and cardiac output that prevents a sustained effect on arterial blood pressure [7]. The unique combination of hyperoxia-induced vasoconstriction and high blood oxygen tension affords an advantage by decreasing a vasogenic component of increased tissue hydrostatic pressure while preserving a high blood-to-tissue oxygen partial pressure gradient and is therefore considered beneficial in crush injury and compartment syndrome [8] as well as brain edema, particularly when the latter develops in situations in which additional indications for HBO therapy exist, such as carbon monoxide poisoning and air embolism [9]. 
Recent experimental evidence supports the role of hyperoxia in cerebral ischemic-anoxic insults such as stroke, head injury, near drowning, asphyxia, and cardiac arrest [10]. In the specific case of traumatic brain injury, it has repeatedly been shown that, although $\mathrm{HBO}$ causes cerebral vasoconstriction, it increases brain tissue $\mathrm{pO}_{2}$ (partial pressure of oxygen) and restores mitochondrial redox potential $[11,12]$. NBO has also been shown to decrease intracranial pressure and improve indices of brain oxidative metabolism in patients with severe head injury [13].

A significant body of experimental data that suggested beneficial effects of hyperoxia in ischemic stroke was followed by clinical trials [14-16] that failed to demonstrate clear-cut benefits. Yet significant shortcomings of the available clinical data call for re-evaluation of the effect of hyperoxia on the outcome of stroke and on the possibility to use it to extend the narrow therapeutic time window for stroke thrombolysis [17].

Another area of controversy is the use of NBO in asphyxiated newborn infants. Initial laboratory and clinical studies suggested an inferior effect of resuscitation with 100\% oxygen compared with room air $[18,19]$. Later cumulative clinical experience $[20,21]$ and systematic review of the literature [22] have not indicated a significant difference in the effectiveness of either gas source or in the final outcome in this specific group of patients. Yet a recent systematic review and meta-analysis of the few available randomized or quasirandomized studies of depressed newborn infants have shown a significant reduction in the risk of mortality and a trend toward a reduction in the risk of severe hypoxic ischemic encephalopathy in newborns resuscitated with $21 \%$ oxygen [23]. Taken together, the available data definitely do not support an overall beneficial effect of hyperoxia in this condition, although the superiority of room air in neonatal resuscitation may still be regarded as controversial.

In contrast to the knowledge on the effects of hyperoxia on central hemodynamics, much less is known about its effects on regional hemodynamics and microhemodynamics. Studies that looked at hyperoxia-induced changes in regional hemodynamics in healthy animals both in normal atmospheric pressure [24-30] and in hyperbaric conditions [24$26,28,31,32$ ] yielded conflicting results, indicating an increase, a decrease, or no change in regional blood flows to specific vascular beds. Only limited and scattered information on regional hemodynamic effects of hyperoxia in relevant models of disease is available. In this regard, a study in an acute canine model of ischemia and reperfusion (IR) of the external iliac artery showed that HBO did not induce vasoconstriction in the affected regional vascular bed until oxygen deficit was corrected [33]. Such findings support suggestions that a dynamic situation may exist in which vasoconstriction is not always effective in severely hypoxic tissues and therefore may not limit the availability of oxygen during hyperoxic exposures and that hyperoxic vasoconstriction may resume after correction of the regional hypoxia. Furthermore, in a severe rat model of hemorrhagic shock, we have shown that normobaric hyperoxia increased vascular resistance in skeletal muscle and did not change splanchnic and renal regional resistances. This yielded redistribution of blood flow to the small intestine and kidneys 'at the expense' of skeletal muscle [34]. A similar divergent effect of normobaric hyperoxia that augmented hind-quarter vascular resistance without a significant effect on the superior mesenteric bed was also found in a rat model of splanchnic IR [35]. In this regard, NBO-induced redistribution of cardiac output to the hepatosplanchnic regions was recently reported in a pig model of severe sepsis [36]. NBO was also shown to redistribute blood flow to ischemic myocardium and improve contractile function during low-flow myocardial ischemia [37]. So the claim that hyperoxia is a universal vasoconstrictor in all vascular beds is an oversimplification both in normal and pathologic states. Furthermore, understanding of the effects of hyperoxia on regional hemodynamics cannot be based on simple extrapolations from healthy humans and animals and warrants careful evaluation in selected clinical states and their animal models.

\section{Effects on inflammation}

Tissue hypoxia activates a large variety of vascular and inflammatory mediators that trigger local inflammation [38] and may lead to a systemic inflammatory response (SIR) that in many cases culminates in multiple organ dysfunction and multiple organ failure (MOF) $[39,40]$. The wish to prevent or treat hypoxia-induced inflammatory responses yielded studies that evaluated the effects of hyperoxia on the microvascularinflammatory response. Most of the attention focused on models of IR which frequently provoke local inflammatory response, SIR, and MOF [40]. The potential beneficial effects of hyperoxia are confronted by the understanding of the central role of reactive oxygen species (ROS) in IR injury [40-42]. The demonstration of increased production of ROS during exposure of normal tissues to hyperoxia evoked concerns that oxygen therapy could exacerbate IR injury. The seemingly rational unease related to the use of hyperoxia in IR must be weighed against a gradually growing body of evidence on beneficial effects of hyperoxia in diverse IR models [42]. Hyperoxia appears to exert a simultaneous effect on a number of steps in the proinflammatory cascades after IR, including interference with polymorphonuclear leukocyte (PMNL) adhesion and production of ROS. In this regard, HBO has been shown to decrease rolling and adhesion of PMNL in the microcirculation following IR of skeletal muscle $[43,44]$, small bowel $[35,45]$, skin flaps [46], heart $[47,48]$, and liver $[49,50]$ as well as after carbon monoxide poisoning [51].

It has been demonstrated by Thom [51] that HBO inhibits PMNL adherence mediated by $\beta_{2}$ integrin glycoproteins CD11/CD18 by impairing cGMP (cyclic guanosine mono- 
phosphate) synthesis in activated leukocytes [52]. Hyperoxia also reduces the expression of the endothelial adhesion molecules E-selectin [53,54] and ICAM-1 (intracellular adhesion molecule-1) [42,52]. Hyperoxia is known to affect the production of nitric oxide (NO) mostly by inducing eNOS (endothelial NO synthase) protein production [55]. Increased NO levels may inhibit PMNL adhesion by inhibition of CD18 function and downregulation of endothelial adhesion molecule synthesis $[55,56]$. Furthermore, it has been shown in ischemic skin flaps that hyperoxia increases local endothelial surface superoxide dismutase activity [46]. This action may diminish the more distal proinflammatory events initiated by ROS after IR, and indeed HBO has been shown to decrease lipid peroxidation and oxidative stress in a number of IR models $[49,51,57,58]$.

HBO was also shown to exert beneficial effects in other inflammatory conditions, including experimental colitis [59,60], Crohn disease [61], carrageenan-induced paw edema [62], and zymossan-induced SIR [63,64]. Detailed mechanisms of the salutary effects of hyperoxia in some of these conditions have not yet been fully elucidated.

In addition to a predominant hyperacute proinflammatory response orchestrated mostly by its effects on PMNLs and macrophages, tissue hypoxia has been shown to provoke subsequent anti-inflammatory responses in macrophages [65-68], to downregulate proinflammatory anti-bacterial functions of $\mathrm{T}$ cells via augmented HIF-1a (hypoxia inducible factor-1a) activity [69], and to weaken local hypoxia-driven and adenosine $A_{2 A}$ receptor-mediated pulmonary anti-inflammatory mechanisms [70]. These observations may represent important subacute effects of hypoxia that help to harness an initial powerful and potentially destructive proinflammatory effect, may be a part of tissue repair processes, or may be an important component of a hypoinflammatory response manifested by some patients with sepsis and acute respiratory distress syndrome (ARDS).

All in all, the ameliorating effects of hyperoxia on the acute net proinflammatory response after IR and other conditions may be related to direct inhibitory effects of oxygen on mechanisms that enhance PMNL rolling, adhesion, activation, and transmigration to tissues. Hyperoxia may also exert indirect effects on the inflammatory response simply by ameliorating tissue hypoxia - a key trigger of inflammation [38]. The effects of hyperoxia on subsequent stages of tissue responses to hypoxia and especially on the anti-inflammatory arm of that response await clarification.

Sepsis is one of the most common clinical causes of SIR. In a study of early hyperdynamic porcine septic shock, Barth and colleagues [36] demonstrated beneficial effects of NBO on apoptosis in the liver and the lungs, on metabolic acidosis, and on renal function. We found a dose-related beneficial effect of NBO (100\% oxygen for 6 hours per day) on the pulmonary inflammatory response in sepsis induced by cecal ligation and puncture (CLP) in rats [71]. Buras and colleagues [72] studied the effects of hyperoxia at 1, 2.5, and 3 ATA applied for 1.5 hours twice a day on survival in a mouse CLP model of sepsis and reported that $\mathrm{HBO}$ at 2.5 ATA improved survival. They also presented data suggesting that augmented production of the anti-inflammatory cytokine interleukin-10 may be an important mechanism of the salutary effects of $\mathrm{HBO}$ in this model [72]. The steadily growing body of data on beneficial effects of hyperoxia in severe local and systemic inflammation warrants appropriate clinical studies to define its role as a clinically relevant modifier of hyperinflammation.

\section{Effects on microorganisms and tissue repair mechanisms}

$\mathrm{HBO}$ has been studied and used in a large variety of infections for over 40 years. Early demonstrations of its beneficial effects in clostridial myonecrosis (gas gangrene) [73] and in chronic refractory osteomyelitis [74] were followed by a large body of experimental data on in vitro effects of increased ambient oxygen partial pressures on microorganisms and reports on in vivo effects of $\mathrm{HBO}$ in infection $[75,76]$. HBO exerts direct bacteriostatic and bactericidal effects mostly on anaerobic microorganisms. These effects have been attributed to deficient defense mechanisms of anaerobic microorganisms against increased production of ROS in hyperoxic environments. Beyond a direct activity against microorganisms, HBO has been shown to re-establish defense mechanisms that are critically impaired by the typically hypoxic microenvironment in infectious sites [77]. Both phagocytosis and microbial killing by PMNLs are severely impaired in hypoxic environments. By increasing tissue oxygen tensions, HBO therapy restores phagocytosis and augments the oxidative burst that is needed for leukocyte microbial killing. Furthermore, the activity of a number of antibiotics is impaired in hypoxic environments and is restored and even augmented during exposure to $\mathrm{HBO}$. Other important beneficial effects of hyperoxia in infection are attributed to enhancement of key components of tissue repair such as necrotic tissue proteolysis, fibroblast proliferation, collagen deposition and angiogenesis, migration of epithelial cells, and bone remodeling by osteoblastic/osteoclastic activity, which are all severely impaired in hypoxic tissues [78]. Altogether, direct activity on bacteria (for example, pseudomonas, some strains of Escherichia, and Clostridium perfringens), improvement of cellular defense mechanisms, synergistic effects on antibiotic activity, modulation of the immune response, and augmentation of mechanisms of tissue repair form the basis for the use of $\mathrm{HBO}$ as adjunctive therapy in combination with antibiotics and surgery for treating tissue infections involving both anaerobic and aerobic microorganisms in hypoxic wounds and tissues [7578] and in sepsis-induced SIR [79].

As for normobaric hyperoxia, two recent prospective randomized clinical studies reported significant beneficial effects of 
perioperative administration of supplemental oxygen (80\% oxygen at normal atmospheric pressure) on surgical site infection (SSI) after elective colorectal surgery [80,81]. A third study [82] on patients undergoing various open abdominal procedures reported a higher incidence of SSI in the higher oxygen group and ignited a yet unsettled debate on the routine use of normobaric hyperoxia to prevent SSI.

Hyperoxia has also been shown to inhibit the growth of some fungi [83-85] and to potentiate the antifungal effect of amphthericin B [84]. Data from case reports, small groups of patients, and compilations of previous reports support the use of adjunctive $\mathrm{HBO}$ treatment together with amphotericin $B$ and surgery in invasive rhinocerebral mucormycosis [85-87]. The level of evidence on the effects of HBO in other fungal infections is less compelling.

The proven pathophysiologic profile of actions of hyperoxia set the basis for its use in selected clinical conditions. Sufficient clinical evidence is available for the use of HBO in carbon monoxide poisoning, decompression sickness, arterial gas embolism, radiation-induced tissue injury, clostridial myonecrosis, problem wounds, crush injury, and refractory osteomyelitis [1]. Effects of NBO in these and in other potentially relevant clinical states are much less studied. Studies that evaluate a range of oxygen doses in both the normobaric and hyperbaric pressure range are largely unavailable and should be encouraged by appropriate allocation of research funding.

\section{Toxicity}

The major limitation confronting a much more liberal clinical use of hyperoxia is its potential toxicity and the relatively narrow margin of safety that exists between its effective and toxic doses. However, an awareness of the toxic effects of oxygen and an acquaintance with safe pressure and duration limits of its application, combined with the ability to carefully manage its dose, provide an acceptable basis for expanding the current list of clinical indications for its use. The most obvious toxic manifestations of oxygen are those exerted on the respiratory system and central nervous system (CNS) [88].

Oxygen toxicity is believed to result from the formation of ROS in excess of the quantity that can be detoxified by the available antioxidant systems in the tissues. Although mechanisms of free radical damage to a substantial array of cellular systems (proteins, enzymes, membrane lipids, and nucleic acids) have already been characterized [88-90], large gaps exist in our understanding of the intermediate stages in the pathophysiologic cascades that follow such reactions and result in functional deficits and clinical phenomena.

The lungs are exposed to higher oxygen tensions than any other organ. At exposures to ambient oxygen pressures of up to $0.1 \mathrm{MPa}$ (1 ATA), the lungs are the first organ to respond adversely to the toxic effects of oxygen. The response involves the entire respiratory tract, including the airway epithelium, microcirculation, alveolar septa, and pleural space. Pulmonary oxygen toxicity is characterized by an initial period in which no overt clinical manifestations of toxicity can be detected - termed the 'latent period'. The duration of this 'silent' clinical interval is inversely proportional to the level of inspired oxygen $[90,91]$.

Acute tracheobronchitis is the earliest clinical syndrome that results from the toxic effects of oxygen on the respiratory system. It does not develop in humans breathing oxygen at partial pressures of below $0.05 \mathrm{MPa}$ (0.5 ATA or $50 \%$ oxygen at normal atmospheric pressure). In healthy humans breathing more than 95\% oxygen at normal atmospheric pressure (0.1 MPa), tracheobronchitis develops after a latent period of 4 to 22 hours and may occur as early as 3 hours while breathing oxygen at $0.3 \mathrm{MPa}$ (3 ATA) $[90,92,93]$. It can start as a mild tickling sensation, later followed by substernal distress and inspiratory pain, which may be accompanied by cough and, when more severe, by a constant retrosternal burning sensation. Tenacious tracheal secretions may accumulate. Upon termination of hyperoxic exposure, the symptoms subside within a few hours, with complete resolution within a few days $[90,92,93]$.

Longer exposures to oxygen (usually more than 48 hours at $0.1 \mathrm{MPa}$ ) may induce diffuse alveolar damage (DAD). The clinical symptoms as well as the laboratory, imaging, and pathologic findings of oxygen-induced DAD are not significantly different from those of ARDS from other causes [94]. Resolution of the acute phase of pulmonary oxygen toxicity or prolonged exposures to oxygen at sublethal concentrations such as during prolonged hyperoxic mechanical ventilation may result in a chronic pulmonary disease characterized by marked residual pulmonary fibrosis and emphysema with tachypnea and progressive hypoxemia $[94,95]$. The relative contributions of hyperoxia, the underlying clinical condition, and mechanical ventilation to the occurrence of chronic pulmonary fibrosis and emphysema in human adults have yet to be clarified.

CNS oxygen toxicity occurs in humans at much higher oxygen pressures, above $0.18 \mathrm{MPa}$ (1.8 ATA) in water and above $0.28 \mathrm{MPa}$ (2.8 ATA) in dry exposures in a hyperbaric chamber. Hence, CNS toxicity does not occur during normobaric exposures but is the main limitation for the use of $\mathrm{HBO}$ in diving and hyperbaric treatments. The 'latent' duration until the appearance of symptoms of CNS oxygen toxicity is inversely related to the oxygen pressure. It may last for more than 4 hours at 0.17 to $0.18 \mathrm{MPa}$ and may be as short as 10 minutes at 0.4 to $0.5 \mathrm{MPa}$.

The most dramatic manifestation of CNS oxygen toxicity is a generalized tonic-clonic (grand mal) seizure [96]. Hyperoxiainduced seizures are believed to be reversible, causing no residual neurologic damage and disappearing upon reduction 
of the inspired oxygen partial pressure [7,96]. Early abnormal changes in cortical electrical activity were reportedly seen on exposure to $\mathrm{HBO}$ a few minutes prior to the full development of the electrical discharges [97]. Unfortunately, no real-time on-line definition of the preseizure electroencephalogram (EEG) activity which could serve as an early EEG indicator of CNS oxygen toxicity is available [98].

Other symptoms of CNS toxicity include nausea, dizziness, sensation of abnormality, headache, disorientation, lightheadedness, and apprehension as well as blurred vision, tunnel vision, tinnitus, respiratory disturbances, eye twitching, and twitching of lips, mouth, and forehead. CNS toxicity does not appear to have warning signs as there is no consistency in the pattern of appearance of symptoms and no typical gradual sequence of minor signs appearing prior to the full development of the seizures [88].

The most dramatic personal factor that may modify the sensitivity to CNS oxygen toxicity is an increase in blood $\mathrm{pCO}_{2}$ (partial pressure of carbon dioxide) [99,100]. Hypercapnia occurs in patients due to hypoventilation, chronic lung diseases, effects of analgesics, narcotics, other drugs, and anesthesia and should be taken into consideration in designing individual hyperoxic treatment protocols. Various pharmacologic strategies were tested in animal models for postponing hyperoxic-induced seizures. However, none of them has shown clinically relevant efficacy [88].

Reversible myopia is a relatively common manifestation of the toxic effects of $\mathrm{HBO}$ on the lens [88]. Cataract formation has been reported after numerous $\mathrm{HBO}$ sessions and is not a real threat during standard protocols. Other possible side effects of hyperbaric therapy are related to barotraumas of the middle ear, sinuses, teeth, or lungs which may result from rapid changes in ambient hydrostatic pressures that occur during the initiation and termination of treatment sessions in a hyperbaric chamber. Proper training of patients and careful adherence to operating instructions decrease the incidence and severity of hyperbaric chamber-related barotraumas to an acceptable minimum.

Due to its potential toxic effects, $\mathrm{HBO}$ is currently restricted to short sessions (less than 2 hours), at pressures below the threshold of CNS toxicity ( $0.28 \mathrm{MPa})$, with 'recovery' breaks of few minutes during which the patient is switched to air breathing at the treatment pressure [1]. As for NBO, whenever possible, it should be restricted to periods shorter than the latent period for development of pulmonary toxicity. When used according to currently employed standard protocols, oxygen therapy is extremely safe.

\section{Conclusions}

This review summarizes the unique profile of physiologic and pharmacologic actions of oxygen that set the basis for its use in human diseases. In contrast to a steadily growing body of

\section{This article is part of a review series on Gaseous mediators, edited by Peter Radermacher.}

Other articles in the series can be found online at http://ccforum.com/series/gaseous_mediators

mechanistic data on hyperoxia, the accumulation of highquality information on its clinical effects lags behind. The current list of evidence-based indications for hyperoxia is much narrower than the wide spectrum of clinical conditions characterized by impaired delivery of oxygen, cellular hypoxia, tissue edema, inflammation, infection, or their combination that could potentially be alleviated by oxygen therapy. Furthermore, most of the available reasonably substantiated clinical data on hyperoxia originate from studies on $\mathrm{HBO}$ which usually did not control for the effects of NBO.

The easy availability of normobaric hyperoxia calls for a much more vigorous attempt to characterize its potential clinical efficacy. The multifaceted beneficial profile of actions of hyperoxia warrants an appropriately funded traditional pharmacologic research approach that will determine the efficacy of a range of safe nontoxic doses (combinations of partial pressure and duration) of hyperoxia in a prospective blinded fashion.

\section{Competing interests}

The author declares that they have no competing interests.

\section{References}

1. Tibbles PM, Edelsberg JS: Hyperbaric-oxygen therapy. N Engl J Med 1996, 334:1642-1648.

2. Borema I, Meyne NG, Brummelkamp WK, Bouma S, Mensch MH, Kamermans F, Stern Hanf M, van Aalderen W: Life without blood. Ned Tijdschr Geneeskd 1960, 104:949-954.

3. Weaver LK, Jopkins RO, Chan KJ, Churchill S, Elliot CG, Clemmer TP, Orme JF, Thomas FO, Morris AH: Hyperbaric oxygen for acute carbon monoxide poisoning. $N$ Engl J Med 2002, 347:1057-1067.

4. Weibel ER: Delivering oxygen to the cells. In The Pathway for Oxygen. Edited by Weibel ER. Boston: Harvard University Press; 1984:175-210.

5. Rivers EP, Ander DS, Powell D: Early goal-directed therapy in the treatment of severe sepsis and septic shock. $N$ Engl J Med 2001, 345:1368-1377.

6. Suttner S, Piper SN, Kumle B, Lang K, Rohn KD, Isgro F, Boldt J: The influence of allogeneic red blood cell transfusion compared with $100 \%$ oxygen ventilation on systemic oxygen transport and skeletal muscle oxygen tension after cardiac surgery. Anesth Analg 2004, 99:2-11.

7. Lambertsen CJ: Effects of oxygen at high partial pressure. In Handbook of Physiology: Respiration. Section 3, volume 2. Edited by Fenn WO, Rahn H. Bethesda, MD: American Physiological Society; 1965:1027-1046.

8. Bouachour G, Cronier P, Gouello, Toulemonde JL, Talha A, Alquier P: Hyperbaric oxygen therapy in the management of crush injuries: a randomized double blind placebo-controlled clinical trial. J Trauma 1996, 41:333-339.

9. Sukoff $\mathrm{MH}$, Ragatz RE: Hyperbaric oxygenation for the treatment of acute cerebral edema. Neurosurg 1982, 10:29-38. 
10. Nemoto EM, Betterman K: Basic physiology of hyperbaric oxygen in brain. Neurosurg Res 2007, 29:116-126.

11. Daugherty WP, Levasseur JE, Sun D, Rockswold GL, Bullock R: Effect of hyperbaric oxygen therapy on cerebral oxygenation and mitochondrial function following moderate lateral fluidpercussion injury in rat. J Neurosurg 2004, 101:499-504.

12. Rockswold SB, Rockswold GL, Defillo A: Hyperbaric oxygen in traumatic brain injury. Neurosurg Res 2007, 29:162-172.

13. Tolias CM, Reinert M, Seiler R, Gilman C, Scharf A, Bullock MR: Normobaric hyperoxia-induced improvement in cerebral metabolism and reduction in intracranial pressure in patients with severe brain injury. J Neurosurg 2004, 101:435-444

14. Anderson DC, Bottini AG, Jagiella WM, Westphal B, Ford S, Rockswold GL, Loewenson RB: A pilot study of hyperbaric oxygen in the treatment of human stroke. Stroke 1991, 22: 1137-1142.

15. Nighoghossian N, Trouillas $P$, Adeleine $P$, Salord E: Hyperbaric oxygen in the treatment of acute ischemic stroke. A double blind pilot study. Stroke 1995, 26:1369-1372.

16. Rusyniac DE, Kirk MA, May JD, Kao LW, Brizendine EJ, Welch JL, Cordell WH, Alonso R: Hyperbaric oxygen therapy in acute ischemic stroke: results of the hyperbaric oxygen in acute ischemic stroke trial pilot study. Stroke 2003, 34:571-574.

17. Singhal $A B$ : Oxygen therapy in stroke: past, present and future. Int J Stroke 2006 4:191-200.

18. Saugstad OD: Resuscitation with room air or oxygen supplementation. Clin Perinatol 1998, 25:741-756.

19. Vento M, Asensi M, Sastre J, Garcia-Sala F, Pallardo FV, Vina J: Resuscitation with room air instead of $100 \%$ oxygen prevents oxidative stress in moderately asphyxiated term neonates. Pediatrics 2001, 107:642-647.

20. Vento M, Asensi M, Sastre J, Garcia-Sala F, Vina J: Six years of experience with the use of room air for the resuscitation of asphyxiated newly born term infants. Biol Neonate 2001, 79: 261-267.

21. Saugstad OD: The role of oxygen in neonatal resuscitation. Clin Perinato/ 2004, 23:431-443.

22. Tan A, Schulze A, O'Donnell CP, Davis AG: Cochrane Database Syst Rev 2005, April 18 (2):CD002273.

23. Saugstad OD, Ramji S, Soll RF, Vento M: Resuscitation of newborn infants with $21 \%$ or $100 \%$ oxygen: an updated systematic review and meta-analysis. Neonatology 2008, 94:176182.

24. Jacobson YG, Defalco AJ, Mundth ED, Keller MA: Hyperbaric oxygen in the therapy of experimental hemorrhagic shock. Surg Forum 1965, 16:15-17.

25. Torbati D, Parolla D, Lavy S: Organ blood flow, cardiac output, arterial blood pressure, and vascular resistance in rats exposed to various oxygen pressures. Aviat Space Environ Med 1979, 50:256-263

26. Onarheim J, Tyssebotn I: Effect of high ambient pressure and oxygen tension on organ blood flow in anesthetized rats. Undersea Biomed Res 1980, 7:47-60.

27. Busing CM, von Gerstenbergk L, Dressler P, Rumm D, Wentz K: Experimental studies on microcirculation under normobaric hyperoxia using the microspheres method. Exp Pathol 1981, 19:146-153.

28. Hordnes C, Tyssebotn I, Onarheim J: Effect of high ambient pressure and oxygen tension on organ blood flow in conscious rats. Acta Physio/ Scand 1982, 114:23A.

29. Matalon S, Nasarajah MS, Farhi LE: Pulmonary and circulatory changes in conscious sheep exposed to $100 \%$ oxygen at 1 ATA. J Appl Physiol 1982, 53:110-116.

30. Plewes JL, Farhi LE: Peripheral circulatory responses to acute hyperoxia. Undersea Biomed Res 1983, 10:123-129.

31. Hahnloser PB, Domanig E, Lanphier E, Shenk WG Jr.: Hyperbaric oxygenation: alterations in cardiac output and regional blood flow. J Thorac Cardiovasc Surg 1966, 52:223-231.

32. Bergo GW, Risberg J, Tyssebotn I: Effect of $\mathbf{5}$ bar oxygen on cardiac output and organ blood flow in conscious rats. Undersea Biomed Res 1988, 15:457-470.

33. Kawamura M, Sakakibara K, Yusa T: Effect of increased oxygen on the peripheral circulation in acute, temporary limb ischemia. J Cardiovasc Surg 1978, 19:161-168.

34. Bitterman H, Brod V, Weiss G, Kushnir D, Bitterman N: The effects of oxygen on regional hemodynamics in hemorrhagic shock. Am J Physiol 1996, 40:H203-H211.
35. Waisman D, Brod V, Wolff R, Sabo E, Chernin M, Weintraub Z, Rotschild A, Bitterman $H$ : Effects of hyperoxia on local and remote microcirculatory inflammatory response after splanchnic ischemia and reperfusion. Am J Physiol 2003, 285: $\mathrm{H} 643-\mathrm{H} 652$.

36. Barth E, Bassi G, Maybauer DM, Simon F, Groger M, Oter S, Speit G, Nguyen CD, Hasel C, Moller P, Wachter U, Vogt JA, Matejovic M, Radermacher P, Calzia E: Effects of ventilation with $100 \%$ oxygen during early hyperdynamic porcine fecal peritonitis. Crit Care Med 2008, 36:495-503.

37. Cason BA, Wisneski J, Neese RA, Stanley WC, Hickey RF, Shnier CB, Gertz EW: Effects of high arterial oxygen tension on function, blood flow distribution, and metabolism in ischemic myocardium. Circulation 1992, 85:828-838.

38. Nathan C: Oxygen and the inflammatory cell. Nature 2003, 17: 675-676.

39. Lefer AM, Lefer DJ: Pharmacology of the endothelium in ischemia-reperfusion and circulatory shock. Annu Rev Pharmacol Toxicol 1993, 33:71-90.

40. Deitch EA: Gut failure: its role in the multiple organ failure syndrome. In Multiple Organ Failure: Pathophysiology and Basic Concepts of Therapy. Edited by Deitch EA. New York: Thieme Medical Publisher; 1990:40-59.

41. Eppihimer MJ, Granger DN: Ischemia/reperfusion-induced leukocyte-endothelial interactions in postcapillary venules. Shock 1997, 8:16-25.

42. Buras J: Basic mechanisms of hyperbaric oxygen in the treatment of ischemia-reperfusion injury. Int Anesthesiol Clin 2000, 38:91-109.

43. Sirsjö A, Lehr HA, Nolte D, Haapaniemi T, Lewis DH, Nylander G, Messmer K: Hyperbaric oxygen treatment enhances the recovery of blood flow and functional capillary density in postischemic striated muscle. Circulatory Shock 1993, 40:913.

44. Zamboni WA, Roth AC, Russell RC, Graham B, Suchy H, Kucan JO: Morphological analysis of the microcirculation during reperfusion of ischemic skeletal muscle and the effect of hyperbaric oxygen. Plast Reconstr Surg 1993, 91:1110-1123.

45. Tjärnström J, Wikström $T$, Bagge U, Risberg $B$, Braide M: Effects of hyperbaric oxygen treatment on neutrophil activation and pulmonary sequestration in intestinal ischemia-reperfusion in rats. Eur Surg Res 1999, 31:147-154.

46. Kaelin CM, Im MJ, Myers RA, Manson PN, Hoopes JE: The effects of hyperbaric oxygen in free flaps in rats. Arch Surg 1990, 125:607-609.

47. Sharifi M, Fares W, Abdel-Karim I, Koch M, Sopko J, Adler D: Usefulness of hyperbaric oxygen therapy to inhibit restenosis after percutaneous coronary intervention for acute myocardial infarction or unstable angina pectoris. Am J Cardio/ 2004, 93:1533-1535.

48. Yogaratnam JZ, Laden G, Madden LA, Seymour AM, Guvendik L, Cowen M, Greenman J, Cale A, Griffin S: Hyprbaric oxygen: a new drug in myocardial revascularization and protection? Cardivasc Revasc Med 2006, 7:146-154.

49. Chen MF, Chen HM, Ueng SWN, Shyr MH: Hyperbaric oxygen pre-treatment attenuates hepatic reperfusion injury. Liver 1998, 18:110-116.

50. Zinchuk VV, Khdorovsky MN, Maslakov DA: Influence of different oxygen modes on the blood oxygen transport and prooxidant-antioxidant status during hepatic ischemia/reperfusion. Physiol Res 2003, 52:533-544.

51. Thom SR: Functional inhibition of leukocyte $\beta 2$ integrins by hyperbaric oxygen in carbon monoxide-mediated brain injury in rats. Toxicol Appl Pharmacol 1993, 123:248-256.

52. Chen $\mathrm{Q}$, Banick PD, Thom SR: Functional inhibition of rat polymorphonuclear leukocyte B2 integrins by hyperbaric oxygen is associated with impaired cGMP synthesis. J Pharmacol Exp Ther 1996, 276:929-933.

53. Buras JA, Reenstra WR: Hyperbaric oxygen decreases endothelial cell $\mathrm{E}$-selectin protein expression in an in-vitro model of ischemia/reperfusion. Ann Emerg Med 1998, 32:S17.

54. Sukhotnik I, Coran AG, Greenblatt R, Brod V, Mogilner J, Shiloni $\mathrm{E}$, Shaoul R, Bitterman $\mathrm{H}$ : Effect of $100 \%$ oxygen on E-selectin expression, recruitment of neutrophils and enterocyte apoptosis following intestinal ischemia-reperfusion in a rat. Pediatr Surg Int 2008, 24:29-35.

55. Buras JA, Stahl GL, Svoboda KS, Reenstra WR: Hyperbaric 
oxygen down-regulates ICAM-1 expression induced by hypoxia and hypoglycaemia: the role of eNOS. Am J Physiol 2000, 278:C292-C302.

56. Banick PD, Chen Q, Xu YA, Thom SR: Nitric oxide inhibits neutrophil $\beta 2$ integrin function by inhibiting membrane-associated cyclic GMP synthesis. J Cell Physio/ 1997, 172:12-24.

57. Mink RB, Dutka AJ: Hyperbaric oxygen after global cerebral ischemia in rabbits does not promote brain lipid peroxidation. Crit Care Med 1995, 23:1398-1404.

58. Sukhotnic I, Brod V, Lurie M, Rahat MA, Shnizer S, Lahat N, Mogilner JG, Bitterman $H$ : The effect of $100 \%$ oxygen on intestinal preservation and recovery following ischemiareperfusion injury in rats. Crit Care Med, in press.

59. Akin ML, Gulluoglu BM, Uluutku H, Erenoglu C, Elbuken E, Yildirim $\mathrm{S}$, Celenk L: Hyperbaric oxygen improves healing in experimental rat colitis. Undersea Hyperbar Med 2002, 29:279-285.

60. Rachmilewitz D, Karmeli F, Okon E, Rubenstein I, Better O: Hyperbaric oxygen: a novel modality to ameliorate experimental colitis. Gut 1998, 43:512-518.

61. Lavy A, Weisz G, Adir Y, Ramon Y, Melamed Y, Eidelman S: Hyperbaric oxygen for perianal Crohn's disease. J Clin Gastroenterol 1994, 19:202-205.

62. Sumen G, Cimsit M, Eroglu L: Hyperbaric oxygen treatment reduces carrageenan-induced acute inflammation in the rat. Eur J Pharmacol 2001, 431:265-268.

63. Luongo $C$, Imperatore $F$, Cuzzocrea S, Fillipelli A, Scafuro MA, Mangoni G, Portolano F, Rossi F: Effects of hyperbaric oxygen exposure on a zymosan-induced shock model. Crit Care Med 1998, 26:1972-1986

64. Imperatore F, Cuzzocrea S, Luongo C, Liguori G, Scafuro A, De Angelis A, Rossi F, Caputi AP, Filippelli A: Hyperbaric oxygen therapy prevents vascular derrangements during zymosaninduced multiple-organ-failure syndrome. Int Care Med 2004, 30:1175-1181.

65. Lahat N, Rahat MA, Ballan M, Weiss-Cerem L, Engelmayer M, Bitterman $\mathrm{H}$ : Hypoxia reduces CD80 expression on monocytes, but enhances their LPS-stimulated TNF $\alpha$ secretion. J Leukocyte Biol 2003, 74:197-2005.

66. Daniliuc S, Bitterman $H$, Rahat MA, Kinarty A, Rosenzweig D, Lahat N: Hypoxia inactivates inducible nitric oxide synthase in mouse macrophages by disrupting its interaction with alphaactinin 4. J Immunol 2003, 171:5631-5640.

67. Rahat MA, Marom B, Bitterman H, Weiss-Cerem L, Kinarty A, Lahat N: Hypoxia reduces the output of matrix metalloproteinase-9 (MMP-9) in monocytes by inhibiting its secretion and elevating membranal association. J Leukocyte Biol 2006, 79:706-718.

68. Lahat N, Rahat MA, Kinarty A, Weiss-Cerem L, Pinchevski L, Bitterman $\mathrm{H}$ : hypoxia enhances lysosomal TNF $\alpha$ degradation in mouse peritoneal macrophages. Am J Physiol 2008 295:C2C12.

69. Thiel M, Caldwell CC, Kreth S, Kuboki S, Chen P, Smith P, Ohta A, Lentsch AB, Lukashev D, Sitkovsky MV: Targeted deletion of HIF-1alpha gene in T cells prevents their inhibition in hypoxic inflamed tissues and improves septic mice survival. PLOS ONE 2007, 2:e853.

70. Thiel M, Chouker A, Ohta A, Jackson E, Caldwell C, Smith P, Lukashev D, Bittmann I, Sitkovsky MV: Oxygenation inhibits the physiological tissue-protecting mechanism and thereby exacerbates acute inflammatory lung injury. PLoS Bio/ 2005, 3:e174.

71. Waisman D, Brod V, Weber G, Lavon O, Popovski F, Vasilenko I, Rahat MA, Lahat N, Bitterman H: Dose-related effects of hyperoxia on the pulmonary inflammatory response in sepsis induced by cecal ligation and puncture. Shock 2006, 25:S54.

72. Buras JA, Holt D, Orlow D, Belikoff B, Pavlides S, Reenstra WR: Hyperbaric oxygen protects from sepsis mortality via an IL-10dependent mechanism. Crit Care Med 2006, 34:2624-2629.

73. Brummelkamp WH, Hogendijk JL, Boerema I: Treatment of anaerobic infections (clostridial myositis) by drenching the tissues with oxygen under high atmospheric pressure. Surgery 1961, 4:299-302.

74. Slack WK, Thomas DA, Perrins D: Hyperbaric oxygenation in chronic osteomyelitis. Lancet 1965, 1:1093-1094.

75. Park M: Effects of hyperbaric oxygen in infectious diseases: basic mechanisms. In Hyperbaric Medicine Practice. 2nd edition. Edited by Kindwall EP, Whelan HT. Flagstaff, AZ: Best Publishing Company; 1999:205-243.
76. Mathieu D, Wattel F: Physiologic effects of hyperbaric oxygen on microorganisms and host defences against infection. In Handbook on Hyperbaric Medicine. Edited by Mathieu D. Dordrecht, The Netherlands: Springer; 2006:103-119.

77. Silver IA: Cellular microenvironment in healing and nonhealing wounds. In Soft and Hard Tissue Repair. Edited by Hunt TK, Heppenstall RB, Pines M. New York: Praeger; 1984:50-66.

78. Gimbel ML, Hunt TK: Wound healing and hyperbaric oxygenation. In Hyperbaric Medicine Practice. 2nd edition. Edited by Kindwall EP, Whelan HT. Flagstaff, AZ: Best Publishing Company; 1999:169-204.

79. Calzia E, Oter S, Muth CM, Radermacher P: The evolving career of hyperbaric oxygen in sepsis: from augmentation of $\mathrm{O}_{2}$ delivery to the modulation of the immune response. Crit Care Med 2006, 34:2693-2695.

80. Greif R, Akca O, Horn EP, Kurz A, Sessler DI: Supplemental perioperative oxygen to reduce the incidence of surgicalwound infection. N Engl J Med 2000, 342:161-167.

81. Belda J, Aguilera L, de la Asuncion JG, Alberti J, Vicente R, Fernandiz L, Rodriguez R, Company B, Sessler DI, Aguilar G, Botello SG, Orti R: Supplemental perioperative oxygen and the risk of surgical wound infection, a randomized controlled study. J Am Med Assoc 2005, 294:2035-2042.

82. Pryor KO, Fahey TJ, Lien CA, Goldstein PA: Surgical site infection and the routine use of perioperative hyperoxia in a general surgical population. J Am Med Assoc 2004, 291:7987.

83. Cairney WJ: Effect of hyperbaric oxygen on certain growth features of Candida albicans. Aviat Space Environ Med 1978, 49:956-958.

84. Gudewicz TM, Mader JT, Davis CP: Combined effects of hyperbaric oxygen and antifungal agents on the growth of Candida albicans. Aviat Space Environ Med 1987, 58:673-678.

85. Ferguson BJ, Mitchell TG, Moon R, Camporesi EM, Farmer J: Adjunctive hyperbaric oxygen for treatment of rhinocerebral mucormycosis. Rev Infect Dis 1988, 10:551-559.

86. Guevara N, Roy D, Dutruc-Rosset C, Santini J, Hofman P, Castillo $\mathrm{L}$ : Mucormycosis - early diagnosis and treatment. Rev Laryngol Otol Rhinol (Bord) 2004, 125:127-131.

87. Yohai RA, Bullock JD, Aziz AA, Markert RJ: Survival factors in rhino-orbital-cerebral mucormycosis. Surv Ophthalmol 1994 39:3-22.

88. Bitterman N, Bitterman H: Oxygen toxicity. In Handbook on Hyperbaric Medicine. Edited by Mathieu D. Dordrecht, The Netherlands: Springer; 2006:731-766.

89. Fisher AB: Oxygen therapy, side effects and toxicity. Am Rev Respir Dis 1980, 122:61-69.

90. Clark JM, Lambertsen CJ: Pulmonary oxygen toxicity: a review. Parmacol Rev 1971, 23:37-133.

91. Lembertsen CJ: Effects of hyperoxia on organs and their tissues. In Lung Biology in Health and Disease. Volume 8. Edited by Lenfant C. New York: Marcel Dekker; 1978:239-303.

92. Clark JM, Lambertsen CJ: Rate of development of pulmonary oxygen toxicity in man during oxygen breathing at 2.0 ATA. $J$ Appl Physiol 1971, 30:739-752.

93. Clark JM, Jackson RM, Lambertsen CJ, Gelfand R, Hiller WD, Unger M: Pulmonary function in men after oxygen breathing at 3.0 ATA for 3.5 h. J Appl Physiol 1991, 71:878-885.

94. Huber GL, Drath DB: Pulmonary oxygen toxicity. In Oxygen and Living Processes. Edited by Gilbert DL. New York: SpringerVerlag; 1981:273-342.

95. Small A: New perspectives on hyperoxic pulmonary toxicity a review. Undersea Biomed Res 1984, 11:1-24.

96. Bitterman N: CNS oxygen toxicity. Undersea Hyperbar Med 2004, 31:63-72.

97. Raday-Bitterman N, Conforti N, Harel D, Lavy S: Analysis of preseizure EEG changes in rats during hyperbaric oxygenation. Exp Neurol 1975, 46:9-19.

98. Geva A, Kerem DH: Forecasting generalized epileptic seizure from the EEG signal by wavelet analysis and dynamic unsupervised fuzzy clustering. IEEE Trans Biomed Eng 1998, 45:1205-1216.

99. Clark JM: Effects of acute and chronic hypercapnia on oxygen tolerance in rats. $J$ Appl Physiol 1981, 50:1036-1044.

100. Arieli R, Ertracht O: Latency to CNS oxygen toxicity in rats as a function of $\mathrm{PCO}_{2}$ and $\mathrm{PO}_{2}$. Eur J Appl Physiol Occup Physiol 1999, 80:598-603. 